\title{
Portal to the heritage of astronomy
}

\section{Rüdiger Schultz}

\author{
Schultz IT Solutions, Diesterweggasse 8 Top 3, AT-1140 Vienna, Austria \\ email: ruediger@schultz.ch
}

\begin{abstract}
Following the Starlight meeting held in La Palma in November 2009, members of the IAU Working Group on Astronomy and World Heritage and the Starlight Initative are working together, with the approval of the UNESCO World Heritage Centre, to produce a new integrated web site for the UNESCO-IAU Astronomy and World Heritage Initiative that will act as a Portal to the Heritage of Astronomy. As such, the portal will be the bridge between the Initiative, the scientific community, National Commissions and experts, and the general public.
\end{abstract}

Keywords. astronomical heritage, world heritage, web portal, UNESCO, ICOMOS

\section{Introduction}

The 'Portal to the Heritage of Astronomy' (www.astronomicalheritage.net) will be the official website of UNESCO's Astronomy and World Heritage Initative, and will enhance global awareness of the various issues connected with astronomical heritage.

Throughout the portal we use the term 'astronomical heritage entity' to refer to different items of astronomical heritage, regardless of their type or any other criteria. These entities are grouped in 'categories of astronomical heritage'. Based on the definitions given in the ICOMOS-IAU Thematic Study on astronomical heritage (Ruggles \& Cotte 2010), we define three cultural categories of astronomical heritage (see Fig. 1), together with an additional natural category for starlight reserves and dark sky areas (ibid.: chapter 16).

Tangible immovable astronomical heritage consists, essentially, of properties (sites and landscapes) that have a strong relationship to astronomy. Currently only this category is

\begin{tabular}{||l|l|l|l|}
\hline & $\begin{array}{c}\text { Tangible immoveable } \\
\text { heritage }\end{array}$ & \multicolumn{1}{|c|}{$\begin{array}{c}\text { Tangible moveable } \\
\text { heritage }\end{array}$} & \multicolumn{1}{|c|}{ Intangible heritage } \\
\hline Property / objects & $\begin{array}{l}\text { Architecture; permanent } \\
\text { constructions and struc- } \\
\text { tures, fixed instruments }\end{array}$ & $\begin{array}{l}\text { Plans; moveable arte- } \\
\text { facts; moveable instru- } \\
\text { ments }\end{array}$ & $\begin{array}{l}\text { Practical/technical ex- } \\
\text { pertise; rules of use and } \\
\text { maintenance; structural/ } \\
\text { architectural history of } \\
\text { the site }\end{array}$ \\
\hline $\begin{array}{l}\text { Results of scientific } \\
\text { activities (in the } \\
\text { broadest sense) }\end{array}$ & $\begin{array}{l}\text { Stone carvings; wall } \\
\text { paintings; iconography; } \\
\text { palaeography; symbolic } \\
\text { representations }\end{array}$ & $\begin{array}{l}\text { Records/accounts of ob- } \\
\text { servations; printed and } \\
\text { digital data; sky maps; } \\
\text { scientific publications }\end{array}$ & $\begin{array}{l}\text { Knowledge and under- } \\
\text { standing; calculations } \\
\text { and theories }\end{array}$ \\
\hline $\begin{array}{l}\text { Socio-cultural } \\
\text { applications and uses }\end{array}$ & $\begin{array}{l}\text { Astronomically aligned } \\
\text { architecture; light-and- } \\
\text { shadow hierophanies; } \\
\text { urban planning and } \\
\text { landscapes constructed } \\
\text { using astronomy }\end{array}$ & $\begin{array}{l}\text { Archives; drawings; } \\
\text { maps and plans, tools or } \\
\text { instruments using } \\
\text { astronomical properties }\end{array}$ & $\begin{array}{l}\text { Calendars; ideology; } \\
\text { predictions of the future } \\
\text { (whether rational or } \\
\text { irrational from modern } \\
\text { perspectives) }\end{array}$ \\
\hline
\end{tabular}

Figure 1. Categories of astronomical heritage and their possible entities, as defined in Ruggles \& Cotte (2010). 
relevant to the World Heritage Convention. Tangible movable heritage consists of instruments, artefacts, archives and documents, while intangible heritage comprises knowledge and ideas. This last category includes indigenous beliefs, calendars, predictions of the future (regardless of whether they are rational from a modern perspective or not), astronomical theories and calculations, documentation, and rules of usage and maintenance.

The portal is intended to be the place where National Commissions for UNESCO go for further information, guidance and support once they seek to promote astronomical heritage sites (cultural or natural) to their national Tentative Lists with a view, in the longer term, to nominating them for inscription onto the World Heritage List. Therefore the portal will provide tools and information for this kind of audience and purpose.

The second targeted audience is the general public interested in astronomical heritage. For this audience, there will be an attractive presentation of astronomical heritage entities, including many that are not properties on the World Heritage List or national Tenative Lists, developed as case studies that raise broader issues. Thus the portal will become a dynamic, publicly accessible database, discussion forum, and document-repository on astronomical heritage entities throughout the world, whether sites on the List or not. If successful, it will become an important vehicle-perhaps 'the' vehicle - for actively supporting, as well as sustaining, political and public interest in the promotion and protection of astronomical heritage sites.

\section{Two dimensions for filtering astronomical heritage}

As the number of astronomical heritage entities presented in the portal is likely to increase rapidly, the portal visitor will need some sort of filter to reduce the list of entities presented to him in a given situation. Two obvious ways in which the portal visitor might wish to filter the entities he is interested in are geographically and temporally. Both of these dimensions can be used as filters, either individually or simultaneously.

Geographical filter. To allow the portal visitor to search for astronomical heritage entities within a certain geographic area, we have implemented a so-called 'Astronomical Heritage Finder' to the portal. Those astronomical heritage entities that are connected to a geographical location are stored with their longitude and latitude, and this information

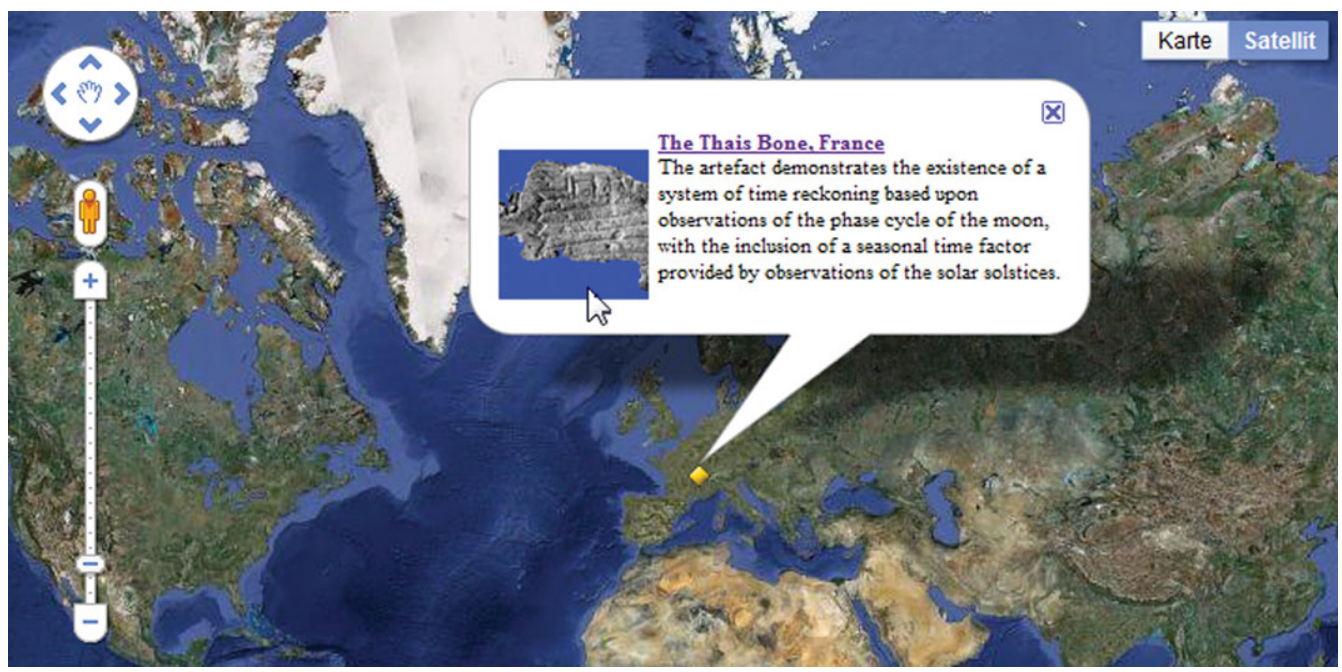

Figure 2. Example of an astronomical heritage entity on the Astronomical Heritage Finder. 


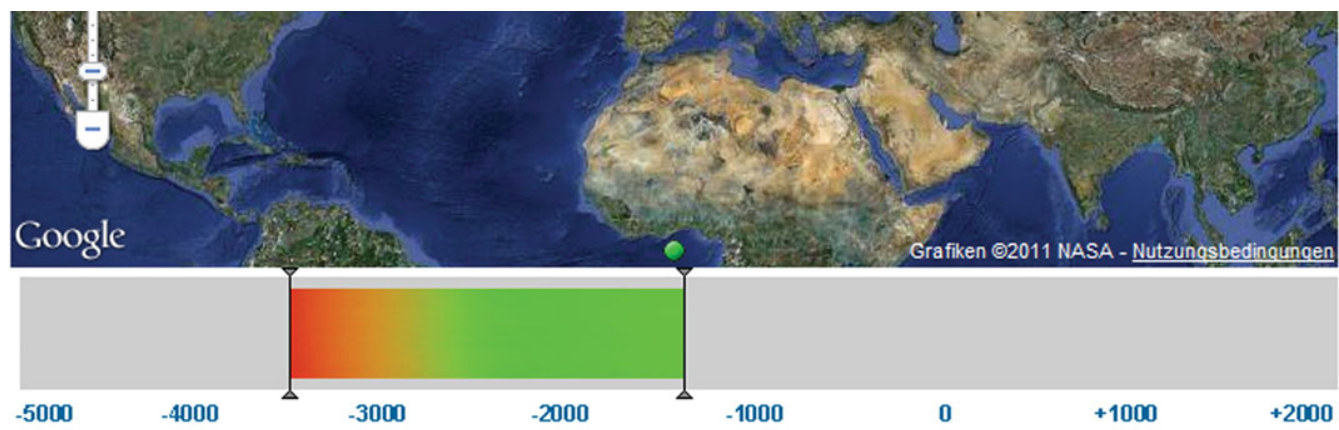

Current timespan set from the year -3550 to the year -1440 . Set timespan filter

Please adjust the two slide controls to select your desired timespan. This will filterlant any entity of Astronomical Heritage,

who's original usage either ended before the starting or started after the ending of your selected timespan.

Figure 3. The Timespan Control, which only presents astronomical heritage entities within a selected timespan.

is used to display a marker for that entity on an interactive website map (using 'Google Maps' functionality). The visitor may now recalibrate the geographical area of interest in a manner that is very commonly used nowadays for websites (see Fig. 2).

Time filter. To allow the portal visitor to search for astronomical heritage entities relevant to a certain period of time, we have also implemented a so-called 'Timespan Control' to the portal. Every astronomical heritage entity is stored with the start year and the end year of its original usage, an estimate being used in cases where this information is uncertain. The system also contains entities whose original usage is still ongoing today. The portal visitor is presented with a kind of slide control, where he can indicate the time span in which he is interested. Every astronomical heritage entity whose original usage ended before the start or started after the end of the selected time span will be filtered out, and therefore will not be visible on the interactive map (see Fig. 3).

It is clearly the case that some astronomical heritage entities will not fit into one or both of these two dimensions, especially those in the category of intangible astronomical heritage. For such entities, we plan a different (not yet finalised) way of presenting them to the general public.

\section{The initial content and its development}

The ICOMOS-IAU Thematic Study on astronomical heritage (Ruggles \& Cotte 2010) is one of two flagship projects undertaken by the IAU Working Group on Astronomy and World Heritage in order to fulfil its commitments under the 2008 Memorandum of Understanding between UNESCO and the IAU. The study was published in June 2010 and officially approved by UNESCO's World Heritage Convention at its meeting in July 2010. The second project is of course the Portal to the Heritage of Astronomy. The portal, however, is not simply another, but rather a successive project. The Thematic Study in its current version will form a major part of the portal's initial content. However, the authors, editors and publishers will continue to discuss, add, change, enhance and publish the contents of the Thematic Study within the portal, so that the online version of the Thematic Study will gradually grow and become different from the June 2010 version. The portal will support this process by implementing the necessary tools within a restricted area and ensuring the consistent and comprehensible growth of the online version. 
The portal will be the gateway to astronomical heritage. For this reason, members of the scientific community will be asked to join in and contribute to its content. There are different ways for them to do so.

- They may wish to submit astronomical heritage entities to the portal using a special website form. The form will request all basic information about the entity and the submitter. These submissions will be discussed, verified and eventually published by an international group of experts (probably an organizational body of the IAU Working Group on Astronomy and World Heritage) by means of a defined process within the portal.

- The portal will also host an event calendar, discussion forum and thematic news feed (RSS feed), to which interested people or groups may contribute their own items connected to astronomical heritage. Again, these contributions will be moderated by a group of international experts, to ensure the relevance of these items to astronomical heritage.

These aspects will enhance the global recognition of the portal (and therefore global awareness of astronomical heritage) and are considered crucial for the success of the project.

\section{Conclusion}

The Portal to the Heritage of Astronomy will form a single gateway between the different communities concerned with, or interested in, astronomical heritage. It is the official web site for UNESCO's Astronomy and World Heritage Initiative and will guide National Commissions and experts towards possible nominations of astronomical heritage entities to the World Heritage List. It will also present astronomical heritage entities to the general public to create global awareness, and it will provide the infrastructure for ongoing work to enhance the Thematic Study. It also will strengthen the scientific community by facilitating communication, cooperation and collaboration in the field of Astronomical Heritage.

\section{References}

Ruggles, C. L. N. \& Cotte, M. 2010, Heritage Sites of Astronomy and Archaeoastronomy in the Context of the UNESCO World Heritage Convention. A Thematic Study, International Council on Monuments and Sites / International Astronomical Union, Paris (downloadable from www.astronomicalheritage.org). 